ease, chiefly on account of its singularity, and not with the expectation of being able to offer any elucidation of its pathology or treatment. To speculate on the former might, until further experience is afforded, be an unprofitable exercise; nevertheless, it is impossible to overlook the important fact of some connexion between the cutaneous deposit and jaundice of aggravated degree and prolonged duration. In every case reported, obstinate and severe jaundice had existed for several months prior to the appearance of the skin malady. Can it be that, like the cretaceous deposits of gout, this was an attempt at elimination of noxions matter necessarily contained in blood, in which was suspended the elements of bile? I regret much that $I$ had no opportunity of instituting a microscopic examination of the deposit; but its primâ facie resemblance to atheroma would warrant the idea that, like the latter exudation, the peculiar deposit in question contained cholesterine, a principle which is well known to enter largely into the composition of the biliary secretion.

This explanation of the composition and pathological significance of the vitiligoid deposit is, as I have premised, simple hypothesis; but, such as it is, I would offer it, in order to elicit observations.

Respecting treatment, nothing can be said. If, as I imagine, the affection is but a symptom of prolonged retention of bile, or its elements in the blood, nothing in the way of amendment can be anticipated unless the original malady be removed, when possibly the absorbonts might spontaneously remove the deposit. In the cases hitherto recorded no deeided amendment followed any of the means adopted.

Felruary, 1853.

\section{ON A NEW SPLINT FOR FRACTURES OF THE LOTVER EXTREMITIES.}

Dy N. HIGHMORE, M.D., Sherborne.

I HAVE several times met with fractures of the extremities which it has been found impossible to reduce so as to bring the bones in anything like a satisfactory position, and I have on more than one occasion seen most serious constitutional effects produced by the violent efforts which were made in attempting their perfect reduction. This has generally occurred in fractures of the lower extremity from direct violence, where the tibia has received a violent blow from the kick of a horse, or a heavy vehicle having passed over it.

It was a case of this kind which occurred about a twelvemonth ago, which induced me to have a new splint made, of which the following are the chief advantages:-

The limb can be placed either in the bent or straight position. Powerful extension can be kept up by means of a screw from the centre of the bottom of the foot, and in a lin : with the tibia, whilst the ankle and knee-joints can be kept in any desired state of flexion or extension. A wound can be dressed on either side, or at the top, as often as may be required, without at all disturbing the limb, the bandages and splint remaining firm, and all lateral movement prevented. This is effected by having two sides to let up and down as required, the hinges being so made by hook and eye that either can be taken off and put on again whilst the limb is completely bandaged, or one side only may be applied so as to admit of poulticing on the other.

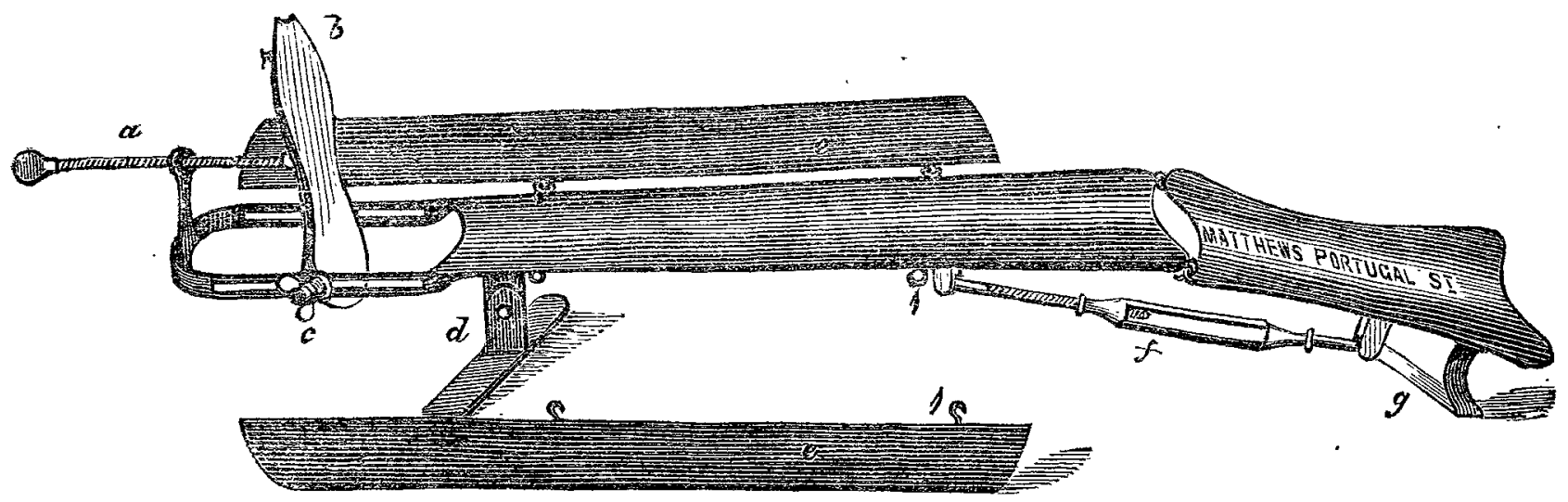

\begin{abstract}
$a$, Extension-screw from the centre of the foot. $b$, Foot-board. $c$, Screw to regulate flexion or extension of ankle-jont. $d$, Support of the splint at the bottom, with rule, joint, and pin to fix it. $e$, The moveable side-pieces. $f$, Screw to regulate flexion or extension of knee-joint. $g$, Support of the splint at the upper end. The use of this is to compensate for the difference in leneth of the thigh -piece and the thigh of a man, which prevents it (in Liston's sphint) from resting on the bed without producing undue pressure on the integumerts of the thigh. $i$, Mook and eye to fix on the side pieces.

This splint can be seen and procured of Mr. Matthews, surgical instrument maker to King's College Hospital, Portugal-street, Lincoln's Inn.
\end{abstract}

I subjoin the following case:-

C. $\mathrm{P}-$, of sober and temperate habits, aged fifty-eight years, fell under a cart which he was driving on the night of the 12th of March, 1851, and the wheel passed over his right leg, producing a fracture of the tibia and fibula. The fracture of the tibia yras obliquely transverse, just below the middle of the bone, with great deformity, from the sharp anterior portion of the lower end projecting upwards under the skin, and there was a round on the inner side of the leg about the size of a fourpenny-piece communicating with the fracture, but not corresponding with the deformity, and no bone protruded through it.

The limb was immediately placed on Liston's splint, and extension made to bring the fractured ends of the bones into apposition, and restore the straight line of the skin. This, kowever, it was found, could not be accomplished with all the force that it was considered justifiable to use; the sharp edge of the lower portion of the tibia sticking up under the skin, and resisting all our attempts to reduce it. It was, however, approximated as nearly as possible, and the wound being covered with lint, saturated with blood, it was left at rest.

During the following week two other ineffectual attempts vere made to reduce the bone. Suppuration had now commenced in the wound; great constitutional disturbance was set up; the whole leg became inflamed; and it being evident that the end of the bone would ulcerate through the skin, I made an opening from the wound at the side entirely across the tibia, which immediately relieved the tension, and I applied a linseed-meal poultice over the whole.

On the 29th I extracted a piece of bone from the wound, rather larger than a finger-nail, and on the $10 \mathrm{th}$ April another piece, both being evidently splinters broken off at the time of the fracture. Suppuration was then going on extensively, with fever, diarrhœa, and great prostration of strength, and there appeared every probability that the man would sink unless amputation was performed, and this he had from the first declared he would never submit to.

Finding, then, that the only chance of saving him was to apply a splint that would fully admit of dressing the wound, whilst lateral support could be given on the sound side, steady extension kept up, and the lower extremity of the tibia at the same time liept down in its place by a fixed flexion of the ankle-joint, and never having seen any apparatus that would efrect all these objects, I went to a smith here, who made the splint, now figured, under my direction, and which has answered its purpose so fully that I do not hesitate to recommend it to the profession. It was applied on the 14 th of April; steady extension was kept up by the screw at the bottom; the wound was regularly dressed by removing one side-piece, without in the least disturbing the other or unbandaging the limb. The patient began at once to mend, four pieces of loosened bone were removed, and he recovered with a very fair and useful limb. The splint was discontinued on the $23 \mathrm{rd}$ of June, when a starched bandage was applied, and the man allowed to get up.

Sherborne, 1853 . 